\title{
Low magnitude mechanical signals mitigate osteopenia without compromising longevity in an aged murine model of spontaneous granulosa cell ovarian cancer
}

\author{
Gabriel Pagnotti ${ }^{1}$, Benjamin J. Adler ${ }^{1}$, Danielle E. Green ${ }^{1}$, Meilin E. Chan ${ }^{1}$, Danielle \\ Frechette $^{1}$, Kenneth R. Shroyer ${ }^{2}$, Wesley G. Beamer ${ }^{3}$, Janet Rubin ${ }^{4}$, and Clinton T. Rubin 1 \\ ${ }^{1}$ Department of Biomedical Engineering, Stony Brook University, Stony Brook, NY, 11794-2580 \\ 2 Department of Pathology, Stony Brook University, Stony Brook, NY, 11794-2580 \\ 3 The Jackson Laboratory, Bar Harbor, ME, 04609 \\ ${ }^{4}$ Department of Medicine, University of North Carolina, Chapel Hill, NC 27599.
}

\section{Abstract}

Cancer progression is often paralleled by a decline in bone mass, raising risk of fracture. Concerns persist regarding anabolic interventions for skeletal protection, as these may inadvertently exacerbate neoplastic tissue expansion. Given bone's inherent mechanosensitivity, low intensity vibration (LIV), a mechanical signal that encourages osteoblastogenesis, could possibly slow cancer-associated bone loss, but this goal must be achieved without fostering disease progression. Seventy $12 \mathrm{w}$ female F1-SWRxSWXJ-9 mice, a strain prone to developing granulosa cell tumors, were randomized into baseline control (BC: $n=10)$, age-matched control (AC: $n=30)$, and LIV $(\mathrm{n}=30)$, which received mechanical signals $(90 \mathrm{~Hz} @ 0.3 \mathrm{~g})$ for $15 \mathrm{~m} / \mathrm{d}, 5 \mathrm{~d} / \mathrm{w}$ over the course of $1 \mathrm{y}$. Survival curves for AC (10 died) and LIV ( 8 died) followed similar trends ( $\mathrm{p}=0.62)$, indicating longevity was unperturbed by LIV. At 1y, bone volume of proximal tibiae in LIV mice was $25 \%$ greater than $\mathrm{AC}(\mathrm{p}<0.02)$, while bone volume of L5 vertebrae was $16 \%$ higher in LIV over AC $(\mathrm{p}<0.02)$. Primary lesions and peripheral metastases were apparent in both LIV and AC; however, overall tumor incidence was approximately $30 \%$ less in LIV ( $\mathrm{p}=0.27)$ and, when disease was evident, involved fewer organ systems $(\mathrm{p}=0.09)$. Marrow-derived mesenchymal stem cells (MSC) were $52 \%$ lower $(\mathrm{p}<0.01)$ in LIV, and $31 \%$ lower $(\mathrm{p}=0.08)$ in mice lacking pathology, suggesting higher MSC levels in this model may have contributed to tumor progression. These experiments indicate that LIV helps protect bone mass in mice inherently susceptible to cancer without compromising life expectancy, perhaps through mechanical control of stem cell fate. Further, these data reflect the numerous system-level benefits of exercise in general, and mechanical signals in particular, in the preservation of bone density and the suppression of cancer progression.

\section{(C) 2012 Elsevier Inc. All rights reserved.}

Corresponding Author: Clinton T. Rubin, Ph.D. Department of Biomedical Engineering Stony Brook University Stony Brook, New York 11794-2580 Phone: (631)-632-2302 Fax: (631)-632-8577 clinton.rubin@ sunysb.edu.

Publisher's Disclaimer: This is a PDF file of an unedited manuscript that has been accepted for publication. As a service to our customers we are providing this early version of the manuscript. The manuscript will undergo copyediting, typesetting, and review of the resulting proof before it is published in its final citable form. Please note that during the production process errors may be discovered which could affect the content, and all legal disclaimers that apply to the journal pertain.

Conflict of Interest:

C. T. Rubin is a founder of Marodyne Medical, Inc. and has a USPTO application under review for the ability of mechanical signals to control metabolic disorders. The other authors declare no competing interests. 


\section{Keywords}

Exercise; Cancer Therapeutics; Mesenchymal Stem Cells

\section{Introduction}

Cancer progression is often complicated by rapid declines in bone density. This osteopenia is exacerbated by the catabolic pressures of radioablative or chemotherapeutic interventions, placing the individual at an elevated risk of fracture [1]. Just as exercise is considered an effective means of reducing the risk of cancer [2], sedentary individuals are at an increased risk of developing tumors at a wide range of anatomic sites [3]. Both cancer and its treatment regimens disrupt adult stem cell reservoirs residing in the bone marrow, populations essential to maintaining and regenerating injured tissues and organs, further suppressing the ability to repair damaged connective tissue [4].

Taking advantage of the skeletal system's inherent sensitivity to mechanical stimuli [5], recent evidence indicates that low-magnitude, high-frequency mechanical signals induced via low intensity vibrations (LIV) are anabolic to bone, perhaps serving as an exercise surrogate by introducing the spectral content of muscle contractibility into the skeletal system [6-11]. To some degree, the osteogenic nature of these mechanical signals is realized by biasing bone marrow-derived MSCs towards osteoblastogenesis, while suppressing the formation of adipose tissue $[12,13]$. Conversely, sedentary individuals, the infirm, or those subject to disuse due to injury, shift the fate of the bone marrow progenitor pool towards adipogenesis $[6,7,13]$, undermining the pool of cells that contribute to skeletal mass [14-16]. These preclinical and clinical data indicate that the absence of mechanical signals potentiates a "default" pathway of fat formation, while physical stimuli, such as exercise, can encourage lineage commitment to higher order connective tissues, including bone, muscle, ligament, and tendon.

The capacity of exercise in general, and LIV in particular, to be anabolic to bone suggests that mechanical signals may be a suitable means of protecting the skeletal system from the catabolic consequences of cancer and its therapies. However, considering the capacity of LIV to influence stem cell activity in the bone marrow [13, 17, 18], it is also reasonable to raise concern that these mechanical signals may enable the formation of a stromal framework of solid tumors [19-22], thus facilitating progression of the disease. This concern is magnified at the molecular level, where $\beta$-catenin, through its cytoplasmic association with the intracellular domain of E-cadherin, serves to partially mediate Wnt/Catenin osteoblastogenic signaling in response to mechanical signals[8], yet as an oncogene it is implicated in a wide array of human cancers [23]. Further, the MSC itself is suggested to be a key component of the tumor microenvironment, with evidence for a role in both suppressing [24], and promoting [25] tumor growth. Recent work which considered MSC harvested from human epithelial ovarian microenvironments showed, in comparison to nonpathological MSCs, that cancer-MSC were able to enhance ovarian tumorigenesis [26]. This suggests that mechanical regulation of MSC commitment could have far-reaching effects on cancer growth, both by driving MSC towards the formation of bone, and/or influencing the progression of the tumor itself.

The experiments reported herein use a mouse model genetically prone to tumorigenesis to determine if the introduction of LIV compromises longevity, protects bone density, promotes tumor formation, and/or biases the fate of bone marrow-derived progenitor populations. The uniqueness of this mouse strain resides in the development of spontaneous granulosa cell tumors (GCT) of the ovary within $\sim 30 \%$ of the population $[27,28]$. 
Tumorigenic onset occurs at approximately 3 months of age, which then proceed to metastasize to the lungs and liver [27-29].

\section{Materials \& Methods}

\subsection{Animal Model}

All experiments and procedures were reviewed and approved by the Stony Brook University Institutional Animal Care and Use Committee (IACUC). An F1 strain of 70 female, SWRXSWXJ-9 mice (The Jackson Laboratory; Bar Harbor, ME), crossbred to create a gct1 mutation, was chosen for its genetic propensity to develop spontaneous granulosa cell tumors at around 3 months of age. Tumorigenesis occurs naturally and spontaneously in these animals, meaning that no external pressures, such as those administered through chemical induction or cell line injection, were used at the beginning time point in the study. Importantly, acquiring the disease is not a certainty in these mice. This mouse strain was selected for that very "attribute," to establish if the mechanical signals influenced the appearance of the disease and/or provoked an early death.

Environmental conditions remained at $12 \mathrm{~h}$ light/dark cycles in a $20^{\circ} \mathrm{C}$ facility. Animals were housed individually, fed ad libitum, and weighed weekly. Distribution of animals into Baseline Control (BC), Age-matched Control (AC), and Low Intensity Vibration (LIV) groups were determined using a Matlab program that specifically randomizes large sample sizes by weight matching.

\subsection{Daily Mechanical Loading Protocol}

The daily loading regimen consisted of placing animals into individual $12 \mathrm{~cm} \times 12 \mathrm{~cm}$ containers on a fixed, vertically-oscillating platform (modified from Marodyne Medical; Lakeland, FL) to administer the LIV signal; $90 \mathrm{~Hz}$ for $15 \mathrm{~min} / \mathrm{d}$ for $5 \mathrm{~d} / \mathrm{w}$ at $0.3 \mathrm{~g} \pm 0.025$ (where $1 \mathrm{~g}=$ Earth's gravitational field, or $9.8 \mathrm{~m} / \mathrm{s}^{2}$ ). The displacements necessary to cause such accelerations at this frequency are less than $100 \mu \mathrm{m}$, and are barely perceptible to human touch. AC underwent identical handling and loading protocols as LIV, but without the platform being activated. Animal age at the beginning of the experimental protocol was 3 months, with the goal of extending the experiment for one year (15mo of age). Other than determining survivability curves, no data from AC or LIV mice that died naturally during that one year experimental period were used in the analyses listed below.

\subsection{Tissue Harvesting and Analysis}

Mice surviving the 1y experimental protocol were first anesthetized using isoflurane inhalation, at which point whole blood was collected via cardiac puncture, heparinized and aliquoted $(100 \mu 1$ ), followed by erythrocyte lysis (1x Pharmalyse; BD Biosciences, San Jose, $C A)$ for FACS analysis. Euthanasia was completed by cervical dislocation. Right tibiae and femora were removed from each mouse and stored in $70 \%$ ethanol (EtOH). Marrow from left tibiae and femora were preserved in Dulbecco's modified eagle's medium containing 2\% FBS, 10mM Hepes Buffer, and 1\% Penicillin-Streptomycin $\left(\mathrm{DMEM}^{+}\right)$for FACS analysis. Tissues for histological staining, including excised tumors, were fixed in $10 \%$ neutral buffered formalin (NBF), replaced at $48 \mathrm{~h}$ with $70 \% \mathrm{EtOH}$. Tissue samples of interest were sectioned and processed in $10 \%$ NBF. $5 \mu \mathrm{m}$, paraffin-embedded tissue sections were stained with hematoxylin and eosin (H\&E). Diagnosis of granulosa cell tumors by histologic examination was confirmed by immunohistochemical staining with calretinin (Abcam; Cambridge, $M A$ ), a molecular marker that is known to be widely expressed in GCT's. To confirm sites of leukocyte recruitment, CD45 staining (BD Pharminogen; San Diego, CA), was also performed, diluted at 1:10,1:20, and 1:50 concentrations following heat antigen 
retrieval in citrate buffer. All analyses were performed blind to the experimental group each animal was in.

\subsection{Flow Cytometry}

Flow cytometric analyses employed the use of a FACSAria cytometer (BD Pharminogen; San Diego, $C A$ ). Fluorescent antibody tagging utilized specific markers (BD Pharminogen; San Diego, $C A$ ) for hematopoietic precursors, MSCs, and immunogenic tissues. Flow cytometry data reported for AC and LIV groups represented the average of all cell populations quantified separately for each animal, processed individually for a single marker. For each sample, cells were homogenized and dissociated from their respective tissues in $3 \mathrm{~mL}$ of $\mathrm{DMEM}^{+}$in order to maximize cell viability before tissue processing. Subsequent washing steps consisted of the addition of DPBS and centrifugation $\left(4^{\circ} \mathrm{C}\right.$, 2000rpm, 10min). $2 \times 10^{6}$ cells from each tissue (with the exception of blood) were quantified individually from each animal using an automated cell counter (Scepter, Millipore; Billerica, $M A$ ), fixed with $1 \%$ neutral buffered formalin (NBF) in Hank's buffered salt solution (HBSS), and stained for specific hematopoietic markers. Specific leukocytes $\left(\mathrm{CD}^{+}\right.$: helper T-cells; $\mathrm{CD}^{+}$: cytotoxic T-cells; CD19+: B cells; CD11c ${ }^{+}$: dendritic cells; $\mathrm{CD}_{3} 35^{+}$: natural killer cells) were quantified based on staining for distinct surface markers. Sca- $1^{+}, \mathrm{c}-\mathrm{kit}^{+}, \mathrm{CD} 90.2^{+}, \mathrm{CD} 105^{+} \& \mathrm{CD} 44^{+}$were designated as unique MSC cell surface identifiers and populations positive for all five markers were sub-gated accordingly [18, 30, 31]. HSC's were quantified using known "LSK" markers (Lineage-, Sca- $1^{+}, \&$ c-kit ${ }^{+}$) in conjunction with side population staining ( Vybrant Dyecycle Violet, Invitrogen; Rockville, $M D)$ [32, 33].

\subsection{Micro-Computed Tomography}

A range of bone morphology parameters of the proximal tibial metaphysis and L5 vertebrae was quantified ex vivo using high-resolution X-ray micro-computed tomography $(\mu \mathrm{CT}$, Scanco Medical; Wayne, PA). These included bone volume (BV), bone volume fraction (BV/TV), trabecular number, thickness and spacing, and Structure Model Index (SMI) [34].

2.5.1. Proximal Tibia-Beginning $300 \mu \mathrm{m}$ distal to the growth plate, $1200 \mu \mathrm{m}$ of the metaphysis was evaluated at $12 \mu \mathrm{m}$ resolution and $55 \mathrm{keV}$ intensity settings. A threshold for each slice was set exclusively for cortical and trabecular bone using an automated script [35]. The reconstructed solid 3D images were then used to quantify bone microarchitecture.

2.5.2. L5 Vertebrae-A $400 \mu \mathrm{m}$ cylindrical sample of trabecular bone from the center of the vertebral body (diameter $=0.8 \mathrm{~mm}$; height $=0.4 \mathrm{~mm}$; comprised of 40 slices at $10 \mu \mathrm{m}$ intervals) at $10 \mu \mathrm{m}$ resolution and $70 \mathrm{keV}$ intensity settings. The reconstructed slices generated a $3 \mathrm{D}$ rendering used to quantify microarchitecture as a representative region of the spine. The axial skeleton was not harvested from BC, so baseline comparisons for L5 could not be made.

\subsection{Statistical Analysis}

Significance ( $\mathrm{p} \unlhd .05$ ) between LIV and AC groups, and between healthy and those animals with visible evidence of tumor pathology upon gross dissection, was determined using Student's t-test. One-way ANOVA was used for $\mu \mathrm{CT}$ analysis for baseline control and Tukey's post hoc with a significance of $\mathrm{p} \unlhd \mathbf{} \mathbf{0}$.05. The Mann-Whitney test was used to determine the Gaussian distribution of the data. A Kaplan Meier Survival Analysis was performed to determine if there was a difference in longevity between LIV and AC. Chisquare tests were performed to determine if the LIV signal influenced the number of animals 
with tumors relative to AC, and if LIV influenced the number of organs with pathology relative to $\mathrm{AC}$.

\section{Results}

\subsection{Longevity}

Over the course of the study, 8 animals were lost within the LIV group (27\%), while 10 were lost in AC (33\%), indicating similar survivability over the 1y course of the study (Fig. $1 ; \mathrm{p}=0.62$ ). Unless otherwise noted, data from animals that died over the course of the study were not included in the analysis.

\subsection{Bone Morphology}

Micro-CT analyses of the proximal tibia indicated that trabecular bone volume (Tb.BV) and bone volume fraction (Tb.BV/TV) in the $64 \mathrm{w}$ old AC had decreased by $-47 \%(\mathrm{p}<0.01)$ and $-45 \%$ ( $\mathrm{p}<0.01$ ), respectively, from $12 \mathrm{w}$ BC (Fig. 2). In contrast, Tb.BV in 64w LIV mice was $+25 \%$ greater $(\mathrm{p}<0.03)$ and $\mathrm{Tb} . \mathrm{BV} / \mathrm{TV}+24 \%$ higher $(\mathrm{p}<0.02)$ than AC. In the axial skeleton, Tb.BV was $+15 \%(\mathrm{p}<0.03)$ and TV.BV/TV was $+16 \%$ higher $(\mathrm{p}<0.02)$ in the L5 vertebrae of LIV mice as compared to AC (Fig. 3). Within the same region of the L5 vertebrae, the structure model index (SMI) was $40 \%$ more plate-like in LIV than AC $(\mathrm{p}<0.01)$. No significant differences between AC and LIV were observed for trabecular number, trabecular thickness, or trabecular spacing. No differences were measured in cortical bone indices.

\subsection{Histology and Pathology}

Animals bearing mature granulosa cell tumors were readily identifiable due to distension of the abdomen. Upon dissection, the most prominent of all lesions were the primary solid ovarian tumors. In certain instances, ovarian cysts measuring up to $8 \mathrm{~mm}^{3}$ were also noted. Histological examination of the tumors revealed sheets of cells with central necrosis, nuclear grooves, Call-Exner bodies, and numerous mitotic figures. Immunohistochemical staining confirmed that these lesions were calretinin ${ }^{+}$and $\mathrm{CD}^{-} 5^{-}$, consistent with the diagnosis of granulosa cell tumors (Fig. 4) [28, 36]. Mature ovarian tumor growth extended from the pelvic cavity into the abdominal cavity. Gross examination of the excised, mature GCT typically revealed adhesion to the kidneys and occasional extension to the thoracic spine.

Upon further inspection of the abdominal cavity, those animals with visually evident tumors were also noted to have enlarged lymph nodes (LN) along the subcutaneous lymphatic vasculature adjacent to the hind-limb musculature, the mediastinum, and in the inguinal regions. Enlarged LN's were found in the para-aortic regions as well but not to the extent as those of the peripheral LN's. Histological examination of the LN's revealed only sinus histiocytosis in some nodes, but in others metastatic granulosa cell tumors with focal necrosis was observed.

Combining the overall incidence of primary tumors and metastatic lesions in the ovaries, peripheral and aortic lymph nodes, liver and lung, this pathology pervaded 54\% of AC mice, while evident in $38 \%$ of LIV who survived to 15 months of age $(\mathrm{p}=0.27)$. A non-significant trend was identified in those mice with pathology evident in multiple organ systems (i.e., liver, ovary, lung), which was approximately $45 \%$ lower in mice subject to the LIV signal $(\mathrm{p}=0.09)$. There was no discernible, qualitative site-specific difference in sites of tumor metastasis or tissue pathology between the groups. 


\subsection{Flow Cytometry}

At the end of the protocol, the $1 \mathrm{y}$ total cell counts quantified from the marrow of $\mathrm{AC}$ and LIV were $12.5 \times 10^{6}$ and $11.5 \times 10^{6}$ cells, respectively, while healthy vs. mice with pathology contained $12.3 \times 10^{6}$ and $11.5 \times 10^{6}$ cells, respectively (nsd). Based on the five positive markers, marrow populations enriched for MSCs were $-52 \%$ lower $(\mathrm{p}=0.01)$ in LIV mice as compared to AC (Fig. 5a, Table 1). Regardless of treatment group, comparing MSCs in mice with no visible pathology versus those containing gross pathologic tissues showed a trend of being $-31 \%$ lower (Fig. $5 b ; \mathrm{p}=0.08$ ). The lower number $(8 \%)$ of HSC-enriched populations in the bone marrow of LIV as compared to AC mice was not significantly different $(\mathrm{p}=0.25$; Table 1). Flow cytometry data was not processed at baseline and, therefore, cannot be used for comparison (simultaneous processing was not possible).

\subsection{Mice with Pathology: LIV vs. AC}

In an effort to evaluate the influence of mechanical signals on those animals with evidence of the disease, bone and MSC parameters were compared between AC and LIV mice with visual evidence of tumor pathology. Tb.BV/TV of the tibia and of the L5 vertebrae of LIV mice bearing pathology showed evidence of a trend towards being higher than $\mathrm{AC}(+17 \%$, $\mathrm{p}=0.12$; and $+13 \%, \mathrm{p}=0.29$, respectively; Fig. 6 ). The population of MSC in the BM of LIV remained significantly lower than AC by $-60 \%(\mathrm{p}<0.04)$.

\section{Discussion}

Osteoporosis, a common co-morbidity of cancer [37], is often exacerbated by aggressive chemo- and radio-therapies [37-41]. Cancer-associated declines in bone strength ultimately increase the risk of fracture, while disease or treatment-based disruption of the bone marrow stem cell pool could compromise the tissue repair process [42]. While antiresorptive agents (e.g., bisphosphonates) have helped cancer patients to mitigate these losses [43-45], concerns arise regarding long term complications, including osteonecrosis of the jaw [46] and atypical fractures of the femur [47]. Further, the skeletal benefits of using anabolic agents may not balance concerns surrounding their role as a potential promoter of neoplastic cell expansion, and thus their use is restricted [48]. In some contrast to pharmacologic strategies, physical activity is universally promoted as a means to help preserve bone density [49]. Unfortunately, the very nature of cancer and/or its treatments is such that participating in even a mild exercise regimen can be difficult [50] and, during extreme bone loss, might precipitate the very fracture it is intended to prevent.

Mechanical signals both large (resulting in >2,000 microstrain at the bone surface) and small ( $<10$ microstrain)[11], several orders of magnitude below those generated by strenuous activity [51], can positively influence bone mass, even under the added duress of disuse [52]. These mechanically-mediated enhancements in bone density are achieved, at least in part, by biasing the MSC population towards formation of skeletal tissue and away from adipose accumulation, most notably by driving MSC differentiation through the Wnt/ $\beta$ catenin pathway [13, 17, 53-55].

To consider the use of mechanical signals as osteoprotective agents while combating cancer, whether or not in concert with cancer treatments, care must be taken to ensure that tumor growth is not accelerated. To this point, $\beta$-catenin - a key mediator of mechanically induced bone remodeling - is known to have a role in tumor growth and metastasis $[23,56]$. The data presented here indicate that brief, daily exposure to extremely low magnitude mechanical signals helped to preserve bone density but did not compromise survivability or promote disease progression in mice with a high propensity for the spontaneous development of GCT. 
GCT's are classified as ovarian stromal tumors and are considered rare in humans, occurring in one out of every 200,000 people per year, comprising just $2 \%$ of all malignancies arising from the ovary [36]. Supporting previous studies which reported the ability of LIV to protect bone morphology $[57,58]$, both the trabecular bone volume and bone volume fraction indices of the tibia and vertebrae in LIV mice were significantly higher than that measured in their AC counterparts. The structure model index (SMI), an index of bone quality [34], indicated that the LIV signal protected trabecular architecture as more plate-like, than rodlike structures, a morphology considered to be stronger and more resilient to fracture [59].

These studies also indicate that the fate of certain bone marrow-derived mesenchymal lineages can be influenced by mechanical loading, with a lower fraction of MSC being measured in bone marrow of the LIV mice as compared to the AC. In parallel, a trend was observed in that MSC-enriched populations were higher in the bone marrow of those mice bearing visible pathology - whether AC or LIV - as compared to those mice lacking tumors evident upon dissection.

The emphasis of the data presented here has been on the comparison of LIV vs. AC mice, and determining if the osteoregulatory potential of mechanical signals also promoted risk of the disease. Nevertheless, as anticipated, mice from each group succumbed to the disease through twelve month protocol, and several from each group showed evidence of pathology when examined at 15 months of age. When considering only those mice with pathology, there was a trend towards higher bone density in the tibia and spine of the LIV group as compared to AC, paralleled by a significantly lower level of MSC in the bone marrow. Whether the lower MSC is simply correlated to a lower tumor burden in the diseased mice, or is actually responsible for the suppression of pathology, cannot be concluded from this study. Nevertheless, when considered with the longevity data, these results suggest that mechanical signals - which perhaps serve as a surrogate to exercise - represent a nonpharmacological means of protecting bone structure in those susceptible to cancer - and those which carry the disease - without enabling the disease itself.

The contributing role of MSC to the tumor microenvironment is controversial, with evidence for both promotion and suppression of tumor progression [24, 25]. In the case of epithelial ovarian carcinoma, not only are MSC "universally present" in human ovarian cancer, but these cancer associated MSCs promoted the growth and abnormal characteristics of cocultured ovarian cell lines in vitro [26]. Our data suggests that not only do mechanical signals have the capacity to suppress MSC number in the bone marrow, but that a corollary is also true - that an increasing tumor burden is associated with an elevated MSC progenitor pool. Importantly, the suppression of the MSC pool by the mechanical signals in the LIV group at 1 year was achieved without affecting HSC levels, indicating that this was cell specific, and not a systemic response per se. As such, the capacity of exercise in general, or mechanical signals distilled from the exertion, may reduce tumor progression by potentially limiting ongoing interactions between MSC and cancer stem cells, while biasing MSC fate towards higher order connective tissues such as bone.

As an indication of the spread of the disease, disparate tumor foci were quantified revealing that enlarged aortic lymph nodes, primarily reflecting increased inflammation, were actually metastatic foci, contributing further to tumor pervasion in addition to the primary ovarian tumors. A role for the suppression of tumor growth by mechanical signals was further supported by a trend of reduced tumor number in the LIV mice, as compared to AC, and the lower number of LIV mice with disease that involved more than one organ system. These data taken in combination with decreased levels of MSC-enriched populations observed in LIV mice are interpreted as a possible reflection of the benefits of exercise in reducing disease pathogenesis, perhaps by driving MSC differentiation towards higher-ordered 
connective tissue, such as bone or muscle, thus hindering their contribution to the stromal framework of neoplastic tissue. This perspective is supported by clinical evidence that sedentary and/or obese individuals are more susceptible to cancer [60,61], indicating that the absence of mechanical signals is permissive to the formation of adipose and neoplastic tissues. Perhaps, in the absence of the regulatory signals commanded by mechanical stimuli, the ability of progenitor populations to proliferate and spread in an undirected manner remains unheeded and unchallenged.

There are a number of limitations in this study, including that the model itself does not approach $100 \%$ onset of tumorigenesis for all animals within 15 months of age (i.e., $66 \%$ of AC suffered from pathology). As the goal of the study was to determine if the mechanical signals promoted appearance of the disease, this uncertainty was considered an attribute of the model, allowing us to compare not only effects on longevity, but on incidence. Importantly, this study reports only the bone loss which occurs with 15 months of aging, rather than the bone loss which may be compounded by chemical or irradiation treatment for cancer, interventions which are certain to accelerate this loss [62]. Nor was the bone lost with age compared to that which might have occurred in a WT control. Nevertheless, the LIV signal did help protect bone quantity and quality in the skeleton, relative to the untreated age-matched controls.

Given the bone morphology measures that were made, we are not able to conclude if this mechanical protection of the skeleton was realized by an increase in bone formation, a suppression of bone resorption, or a change in levels of bone turnover. As this is an ovarian cancer, however, fluctuating hormone levels, such as that of estrogen, derived from dysplasia might contribute to variances in normal trabecular bone remodeling, a point of consideration for future work in elucidating the underlying mechanism-of-action. Severe osteolysis that is observed in occult prostate and breast skeletal metastases and primary lesions of multiple myeloma, do not appear in this model.

Follow-up studies will examine the ability of mechanical signals to suppress bone loss and cancer progression in induced models of the disease, with a continued focus on the lineage selection of the mesenchymal progenitor. It should also be pointed out that the lineage selection (FACS) data were only compared at the endpoint, with no comparison to baseline measures. While this would have provided a strong index of change, confidence in the measures is typically derived only from measures made at the same sacrifice date, using the same reagents; something that was not possible given the difficulty of breeding these mice. As importantly, in vitro studies must be used to determine if, and how, hyperplasia in cancer cells can be suppressed by mechanical signals, perhaps through pathways already identified as mechano-responsive in MSC [63].

\section{Conclusion}

In summary, using a mouse model of spontaneous granulosa cell ovarian cancer, low magnitude mechanical signals, induced non-invasively using low intensity vibration, mitigated the long-term loss of bone relative to age-matched controls. This skeletal endpoint was achieved without compromising survival. Further, the decreased tumor burden, considered in concert with significantly lower mesenchymal stem cell populations measured in the LIV mice, suggest both the skeletal and disease benefits of mechanical-based interventions, including exercise, may involve biasing these progenitors towards higherorder connective tissues such as bone. Considering the brief exposure and low magnitude of these mechanical signals, these preliminary data support the potential of low intensity vibration for the suppression of bone loss in cancer patients, particularly those that are 
infirm or are inactive, safely achieved without the use of drugs which might otherwise complicate treatments for the disease itself.

\section{Acknowledgments}

Funding:

This work was supported by National Institute of Health grant AR 43498 and the Center for Biotechnology, Stony Brook University.

\section{References}

1. Al-Tonbary YA, El-Ziny MA, Elsharkawy AA, El-Hawary AK, El-Ashry R, Fouda AE. Bone mineral density in newly diagnosed children with neuroblastoma. Pediatr Blood Cancer. 2011; 56:202-5. [PubMed: 21157889]

2. Kushi LH, Byers T, Doyle C, Bandera EV, McCullough M, McTiernan A, Gansler T, Andrews KS, Thun MJ. American Cancer Society Guidelines on Nutrition and Physical Activity for cancer prevention: reducing the risk of cancer with healthy food choices and physical activity. CA Cancer J Clin. 2006; 56:254-81. quiz 313-4. [PubMed: 17005596]

3. Cancer NIo. Cancer Trends Progress Report - 2007. 2009.

4. Wang R, Chadalavada K, Wilshire J, Kowalik U, Hovinga KE, Geber A, Fligelman B, Leversha M, Brennan C, Tabar V. Glioblastoma stem-like cells give rise to tumour endothelium. Nature. 2010; 468:829-33. [PubMed: 21102433]

5. Wolff, J. The Law Of Bone Remodeling. Springer; Berlin: 1986.

6. Ozcivici E, Luu YK, Adler B, Qin YX, Rubin J, Judex S, Rubin CT. Mechanical signals as anabolic agents in bone. Nat Rev Rheumatol. 2010; 6:50-9. [PubMed: 20046206]

7. Rubin C, Xu G, Judex S. The anabolic activity of bone tissue, suppressed by disuse, is normalized by brief exposure to extremely low-magnitude mechanical stimuli. FASEB J. 2001; 15:2225-9. [PubMed: 11641249]

8. Sen B, Xie Z, Case N, Ma M, Rubin C, Rubin J. Mechanical strain inhibits adipogenesis in mesenchymal stem cells by stimulating a durable beta-catenin signal. Endocrinology. 2008; 149:6065-75. [PubMed: 18687779]

9. Judex S, Gupta S, Rubin C. Regulation of mechanical signals in bone. Orthod Craniofac Res. 2009; 12:94-104. [PubMed: 19419452]

10. Rubin C, Judex S, Qin YX. Low-level mechanical signals and their potential as a nonpharmacological intervention for osteoporosis. Age Ageing. 2006; 35(Suppl 2):ii32-ii36. [PubMed: 16926201]

11. Rubin C, Turner AS, Bain S, Mallinckrodt C, McLeod K. Anabolism. Low mechanical signals strengthen long bones. Nature. 2001; 412:603-4. [PubMed: 11493908]

12. Rubin CT, Capilla E, Luu YK, Busa B, Crawford H, Nolan DJ, Mittal V, Rosen CJ, Pessin JE, Judex S. Adipogenesis is inhibited by brief, daily exposure to high-frequency, extremely lowmagnitude mechanical signals. Proc Natl Acad Sci U S A. 2007; 104:17879-84. [PubMed: 17959771]

13. Sen B, Xie Z, Case N, Ma M, Rubin C, Rubin J. Mechanical strain inhibits adipogenesis in mesenchymal stem cells by stimulating a durable beta-catenin signal. Endocrinology. 2008; 149:6065-6075. [PubMed: 18687779]

14. Schuster DP. Changes in physiology with increasing fat mass. Semin Pediatr Surg. 2009; 18:12635. [PubMed: 19573754]

15. Cao JJ. Effects of obesity on bone metabolism. J Orthop Surg Res. 2011; 6:30. [PubMed: 21676245]

16. Moerman EJ, Teng K, Lipschitz DA, Lecka-Czernik B. Aging activates adipogenic and suppresses osteogenic programs in mesenchymal marrow stroma/stem cells: the role of PPAR-gamma2 transcription factor and TGF-beta/BMP signaling pathways. Aging Cell. 2004; 3:379-89. [PubMed: 15569355] 
17. Sen B, Xie Z, Case N, Styner M, Rubin CT, Rubin J. Mechanical signal influence on mesenchymal stem cell fate is enhanced by incorporation of refractory periods into the loading regimen. $\mathrm{J}$ Biomech. 2010

18. Luu YK, Capilla E, Rosen CJ, Gilsanz V, Pessin JE, Judex S, Rubin CT. Mechanical stimulation of mesenchymal stem cell proliferation and differentiation promotes osteogenesis while preventing dietary-induced obesity. J Bone Miner Res. 2009; 24:50-61. [PubMed: 18715135]

19. Li L, Tian H, Yue W, Zhu F, Li S, Li W. Human mesenchymal stem cells play a dual role on tumor cell growth in vitro and in vivo. J Cell Physiol. 2011; 226:1860-7. [PubMed: 21442622]

20. Roorda BD, ter Elst A, Kamps WA, de Bont ES. Bone marrow-derived cells and tumor growth: contribution of bone marrow-derived cells to tumor micro-environments with special focus on mesenchymal stem cells. Crit Rev Oncol Hematol. 2009; 69:187-98. [PubMed: 18675551]

21. Studeny M, Marini FC, Dembinski JL, Zompetta C, Cabreira-Hansen M, Bekele BN, Champlin RE, Andreeff M. Mesenchymal stem cells: potential precursors for tumor stroma and targeteddelivery vehicles for anticancer agents. J Natl Cancer Inst. 2004; 96:1593-603. [PubMed: 15523088]

22. Spaeth EL, Dembinski JL, Sasser AK, Watson K, Klopp A, Hall B, Andreeff M, Marini F. Mesenchymal stem cell transition to tumor-associated fibroblasts contributes to fibrovascular network expansion and tumor progression. PLoS One. 2009; 4:e4992. [PubMed: 19352430]

23. Morin PJ. beta-catenin signaling and cancer. Bioessays. 1999; 21:1021-30. [PubMed: 10580987]

24. Qiao L, Xu ZL, Zhao TJ, Ye LH, Zhang XD. Dkk-1 secreted by mesenchymal stem cells inhibits growth of breast cancer cells via depression of Wnt signalling. Cancer Lett. 2008; 269:67-77. [PubMed: 18571836]

25. Karnoub AE, Dash AB, Vo AP, Sullivan A, Brooks MW, Bell GW, Richardson AL, Polyak K, Tubo R, Weinberg RA. Mesenchymal stem cells within tumour stroma promote breast cancer metastasis. Nature. 2007; 449:557-63. [PubMed: 17914389]

26. McLean K, Gong Y, Choi Y, Deng N, Yang K, Bai S, Cabrera L, Keller E, McCauley L, Cho KR, Buckanovich RJ. Human ovarian carcinoma-associated mesenchymal stem cells regulate cancer stem cells and tumorigenesis via altered BMP production. J Clin Invest. 2011

27. Beamer WG, Hoppe PC, Whitten WK. Spontaneous malignant granulosa cell tumors in ovaries of young SWR mice. Cancer Res. 1985; 45:5575-81. [PubMed: 4053032]

28. Gocze PM, Beamer WG, de Jong FH, Freeman DA. Hormone synthesis and responsiveness of spontaneous granulosa cell tumors in $($ SWR $\times$ SWXJ-9) F1 mice. Gynecol Oncol. 1997; 65:143-8. [PubMed: 9103404]

29. Beamer WG, Shultz KL, Tennent BJ, Azumi N, Sundberg JP. Mouse model for malignant juvenile ovarian granulosa cell tumors. Toxicol Pathol. 1998; 26:704-10. [PubMed: 9789961]

30. Soleimani M, Nadri S. A protocol for isolation and culture of mesenchymal stem cells from mouse bone marrow. Nat Protoc. 2009; 4:102-6. [PubMed: 19131962]

31. Zhou YF, Bosch-Marce M, Okuyama H, Krishnamachary B, Kimura H, Zhang L, Huso DL, Semenza GL. Spontaneous transformation of cultured mouse bone marrow-derived stromal cells. Cancer Res. 2006; 66:10849-54. [PubMed: 17108121]

32. Challen GA, Boles N, Lin KK, Goodell MA. Mouse hematopoietic stem cell identification and analysis. Cytometry A. 2009; 75:14-24. [PubMed: 19023891]

33. Weksberg DC, Chambers SM, Boles NC, Goodell MA. CD150- side population cells represent a functionally distinct population of long-term hematopoietic stem cells. Blood. 2008; 111:2444-51. [PubMed: 18055867]

34. Judex S, Garman R, Squire M, Donahue LR, Rubin C. Genetically based influences on the sitespecific regulation of trabecular and cortical bone morphology. J.Bone Miner.Res. 2004; 19:600606. [PubMed: 15005847]

35. Lublinsky S, Ozcivici E, Judex S. An automated algorithm to detect the trabecular-cortical bone interface in micro-computed tomographic images. Calcif Tissue Int. 2007; 81:285-93. [PubMed: 17828460]

36. Sehouli J, Drescher FS, Mustea A, Elling D, Friedmann W, Kuhn W, Nehmzow M, Opri F, Klare P, Dietel M, Lichtenegger W. Granulosa cell tumor of the ovary: 10 years follow-up data of 65 patients. Anticancer Res. 2004; 24:1223-9. [PubMed: 15154651] 
37. Vassilopoulou-Sellin R, Brosnan P, Delpassand A, Zietz H, Klein MJ, Jaffe N. Osteopenia in young adult survivors of childhood cancer. Med Pediatr Oncol. 1999; 32:272-8. [PubMed: 10102021]

38. Mazziotti G, Canalis E, Giustina A. Drug-induced osteoporosis: mechanisms and clinical implications. Am J Med. 123:877-84. [PubMed: 20920685]

39. Holmes SJ, Whitehouse RW, Clark ST, Crowther DC, Adams JE, Shalet SM. Reduced bone mineral density in men following chemotherapy for Hodgkin's disease. Br J Cancer. 1994; 70:3715. [PubMed: 8054287]

40. Cao X, Wu X, Frassica D, Yu B, Pang L, Xian L, Wan M, Lei W, Armour M, Tryggestad E, Wong J, Wen CY, Lu WW, Frassica FJ. Irradiation induces bone injury by damaging bone marrow microenvironment for stem cells. Proc Natl Acad Sci U S A. 2011; 108:1609-14. [PubMed: 21220327]

41. Baxter NN, Habermann EB, Tepper JE, Durham SB, Virnig BA. Risk of pelvic fractures in older women following pelvic irradiation. JAMA. 2005; 294:2587-93. [PubMed: 16304072]

42. Kwong FN, Harris MB. Recent developments in the biology of fracture repair. J Am Acad Orthop Surg. 2008; 16:619-25. [PubMed: 18978283]

43. Pountos I, Georgouli T, Blokhuis TJ, Pape HC, Giannoudis PV. Pharmacological agents and impairment of fracture healing: what is the evidence? Injury. 2008; 39:384-94. [PubMed: 18316083]

44. Theriault RL. The role of bisphosphonates in breast cancer. J Natl Compr Canc Netw. 2003; 1:232-41. [PubMed: 19768882]

45. Coleman R. The use of bisphosphonates in cancer treatment. Ann N Y Acad Sci. 2011; 1218:3-14. [PubMed: 20946581]

46. Ruggiero SL, Mehrotra B, Rosenberg TJ, Engroff SL. Osteonecrosis of the jaws associated with the use of bisphosphonates: a review of 63 cases. J.Oral Maxillofac.Surg. 2004; 62:527-534. [PubMed: 15122554]

47. Black DM, Kelly MP, Genant HK, Palermo L, Eastell R, Bucci-Rechtweg C, Cauley J, Leung PC, Boonen S, Santora A, de Papp A, Bauer DC. Bisphosphonates and fractures of the subtrochanteric or diaphyseal femur. N Engl J Med. 2010; 362:1761-71. [PubMed: 20335571]

48. Orwoll ES, Scheele WH, Paul S, Adami S, Syversen U, Diez-Perez A, Kaufman JM, Clancy AD, Gaich GA. The effect of teriparatide [human parathyroid hormone (1-34)] therapy on bone density in men with osteoporosis. J.Bone Miner.Res. 2003; 18:9-17. [PubMed: 12510800]

49. Friedenreich CM, Woolcott CG, McTiernan A, Ballard-Barbash R, Brant RF, Stanczyk FZ, Terry T, Boyd NF, Yaffe MJ, Irwin ML, Jones CA, Yasui Y, Campbell KL, McNeely ML, Karvinen KH, Wang Q, Courneya KS. Alberta physical activity and breast cancer prevention trial: sex hormone changes in a year-long exercise intervention among postmenopausal women. J.Clin.Oncol. 2010; 28:1458-1466. [PubMed: 20159820]

50. Brown JK, Byers T, Doyle C, Coumeya KS, Demark-Wahnefried W, Kushi LH, McTieman A, Rock CL, Aziz N, Bloch AS, Eldridge B, Hamilton K, Katzin C, Koonce A, Main J, Mobley C, Morra ME, Pierce MS, Sawyer KA. Nutrition and physical activity during and after cancer treatment: an American Cancer Society guide for informed choices. CA Cancer J Clin. 2003; 53:268-91. [PubMed: 14570227]

51. Rubin CT, Lanyon LE. Dynamic strain similarity in vertebrates; an alternative to allometric limb bone scaling. J.Theor.Biol. 1984; 107:321-327. [PubMed: 6717041]

52. Rubin C, Xu G, Judex S. The anabolic activity of bone tissue, suppressed by disuse, is normalized by brief exposure to extremely low-magnitude mechanical stimuli. FASEB J. 2001; 15:22252229. [PubMed: 11641249]

53. Sen B, Styner M, Xie Z, Case N, Rubin CT, Rubin J. Mechanical loading regulates NFATc1 and beta-catenin signaling through a GSK3beta control node. J Biol Chem. 2009; 284:34607-17. [PubMed: 19840939]

54. Case N, Rubin J. Beta-catenin--a supporting role in the skeleton. J Cell Biochem. 2010; 110:54553. [PubMed: 20512915] 
55. Pittenger MF, Mackay AM, Beck SC, Jaiswal RK, Douglas R, Mosca JD, Moorman MA, Simonetti DW, Craig S, Marshak DR. Multilineage potential of adult human mesenchymal stem cells. Science. 1999; 284:143-7. [PubMed: 10102814]

56. Pontes J Jr. Srougi M, Borra PM, Dall' Oglio MF, Ribeiro-Filho LA, Leite KR. E-cadherin and beta-catenin loss of expression related to bone metastasis in prostate cancer. Appl Immunohistochem Mol Morphol. 2010; 18:179-84. [PubMed: 18685493]

57. Gilsanz V, Wren TA, Sanchez M, Dorey F, Judex S, Rubin C. Low-level, high-frequency mechanical signals enhance musculoskeletal development of young women with low BMD. J Bone Miner Res. 2006; 21:1464-74. [PubMed: 16939405]

58. Ward K, Alsop C, Caulton J, Rubin C, Adams J, Mughal Z. Low magnitude mechanical loading is osteogenic in children with disabling conditions. J Bone Miner Res. 2004; 19:360-9. [PubMed: 15040823]

59. Warden SJ, Fuchs RK, Castillo AB, Nelson IR, Turner CH. Exercise when young provides lifelong benefits to bone structure and strength. J.Bone Miner.Res. 2007; 22:251-259. [PubMed: 17129172]

60. Weiderpass E. Lifestyle and cancer risk. J Prev Med Public Health. 2010; 43:459-71. [PubMed: 21139406]

61. World Health Organization. Global health risks : mortality and burden of disease attributable to selected major risks. World Health Organization; Geneva, Switzerland: 2009.

62. Green DE, Adler BJ, Chan ME, Rubin CT. Devastation of adult stem cell pools by irradiation precedes collapse of trabecular bone quality and quantity. J Bone Miner Res. 2011

63. Sen B, Guilluy C, Xie Z, Case N, Syner M, Thomas J, Oguz I, Rubin CT, Burridge K, Rubin J. Mechanically induced focal adhesion assembly amplifies anti-adipogenic pathways in mesenchymal stem cells. Stem Cells. 2011 


\section{Highlights}

- LIV effects on bone were examined in mice prone to granulosa cell tumorigenesis.

- Exposure to LIV did not compromise longevity following 1y of treatment.

- Bone preservation was evident in tibiae and vertebrae of LIV compared to controls.

- MSCs were significantly lower in LIV-treated animals and in those lacking pathology.

- Overall tumor incidence was lower in LIV involving fewer organs when disease was evident. 


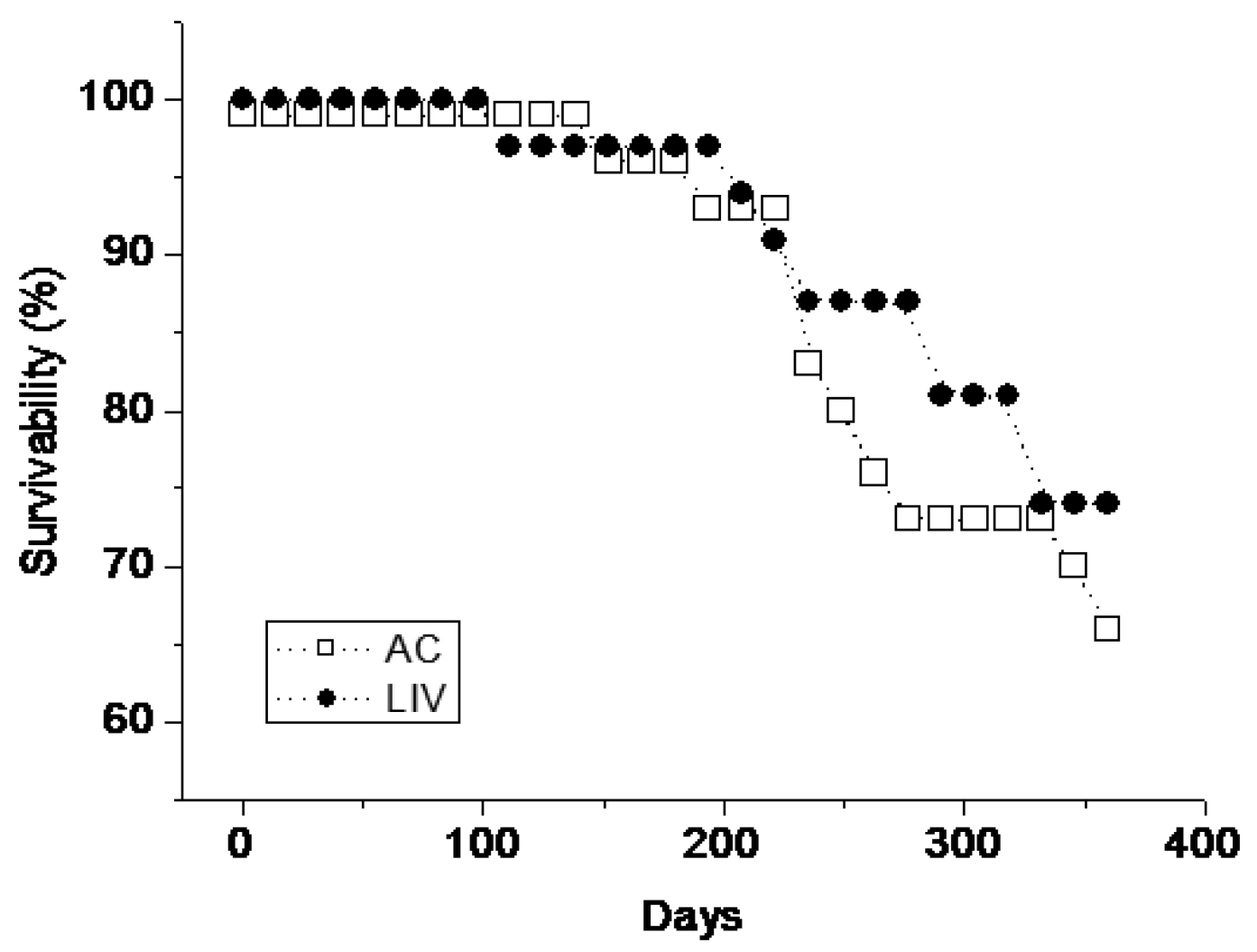

Figure 1.

Survivability curve for LIV $(n=30)$ and AC $(n=30)$ mice, with the experimental protocol beginning at 3 months of age. Both AC and LIV groups followed similar declines over the course of the 1 year period $(\mathrm{p}=0.62)$, indicating that exposure to the mechanical signal did not compromise life expectancy. 

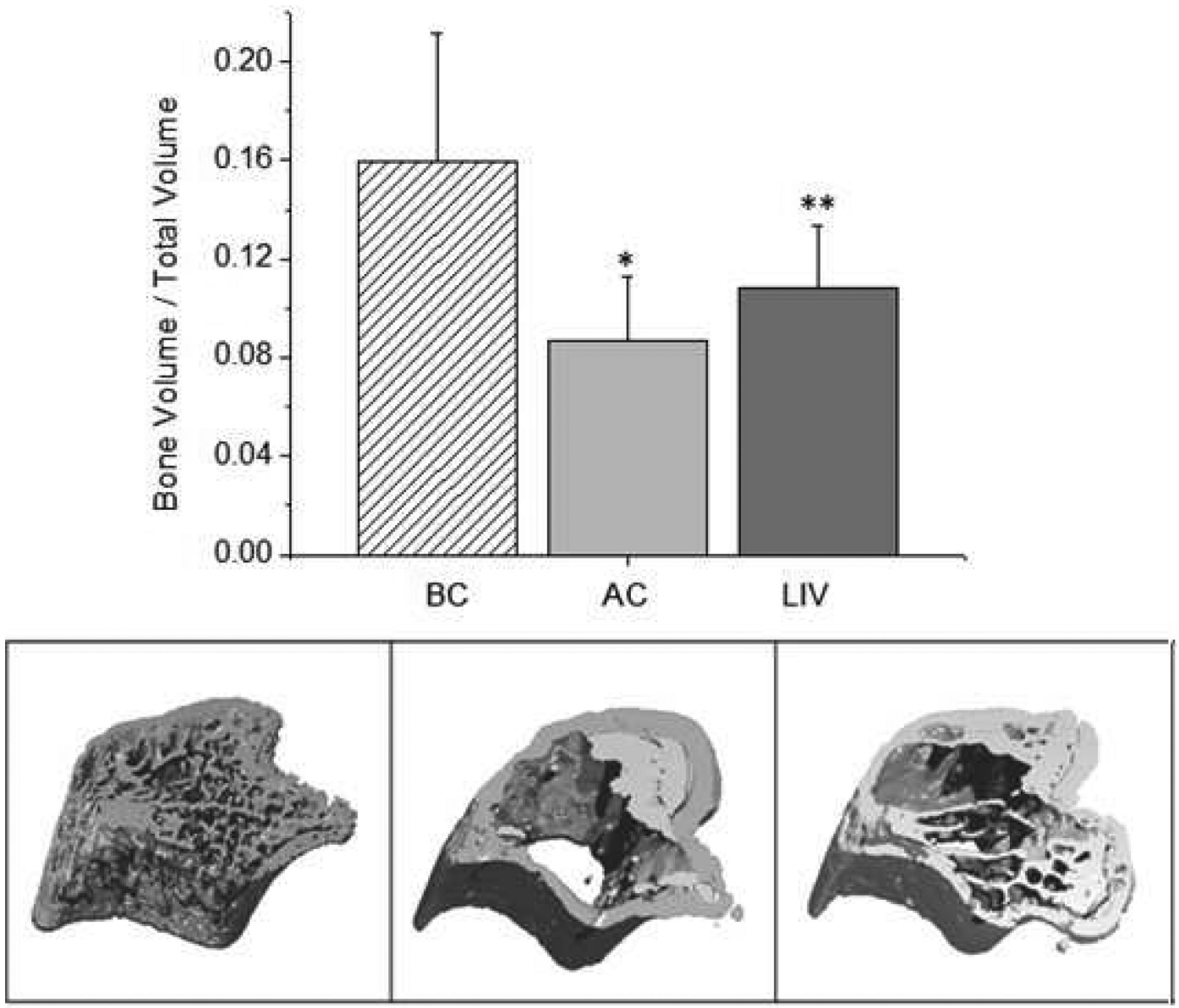

Figure 2.

Reconstructions of cortical (gray) and trabecular (pink) bone in the tibial metaphysis, assayed by $\mu \mathrm{CT}$, are shown for baseline control (Left: $3 \mathrm{mo}$ of age), age-matchedcontrol (Center: 15mo), and low intensity vibration mice (Right: $15 \mathrm{mo}$ ). While bone quantity (BV/ TV) dropped relative to baseline (BC) in both age-matched control (AC) and the mechanically stimulated (LIV) mice, the loss was mitigated in LIV by daily exposure to the mechanical signals (AC \& LIV both different than $\mathrm{BC}$ at $\mathrm{p}<0.01$, shown by *; AC different from LIV at $\mathrm{p}<0.02$, shown by $* *)$. 
Region of Interest
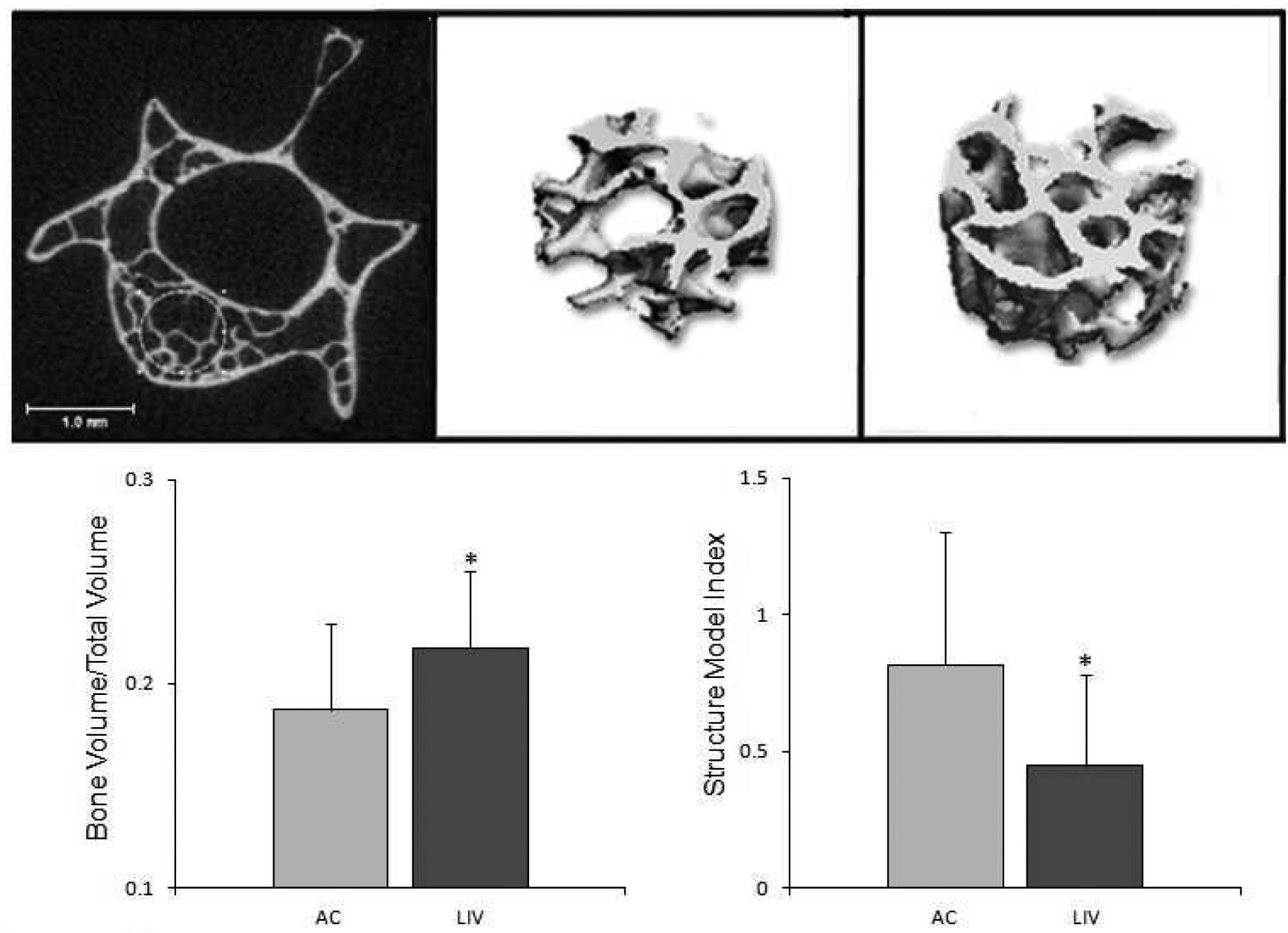

Figure 3.

Reconstructions of trabecular bone volume as derived from $\mu$ CT scans of L5. A cylinder, $0.8 \mathrm{~mm}$ in diameter and $0.4 \mathrm{~mm}$ high, was fit into the center of the vertebral body (top left; Region of Interest represented by dashed line), such that a defined volume was taken for each specimen. The 3D reconstruction of the LIV mice (top right), revealed a bone volume fraction, Tb.BV/TV, to be $+16 \%$ higher than that of the age matched controls (bottom left; $\mathrm{p}<0.02$ ). The SMI, $40 \%$ different between groups (bottom right; $\mathrm{p}<0.01$ ), indicated the trabecular morphology of the mechanically stimulated mice to be more plate-like in structure, rather than the rod-like struts measured in the age-matched controls. Scale is $1 \mathrm{~mm}$; $*=p<0.02$. 


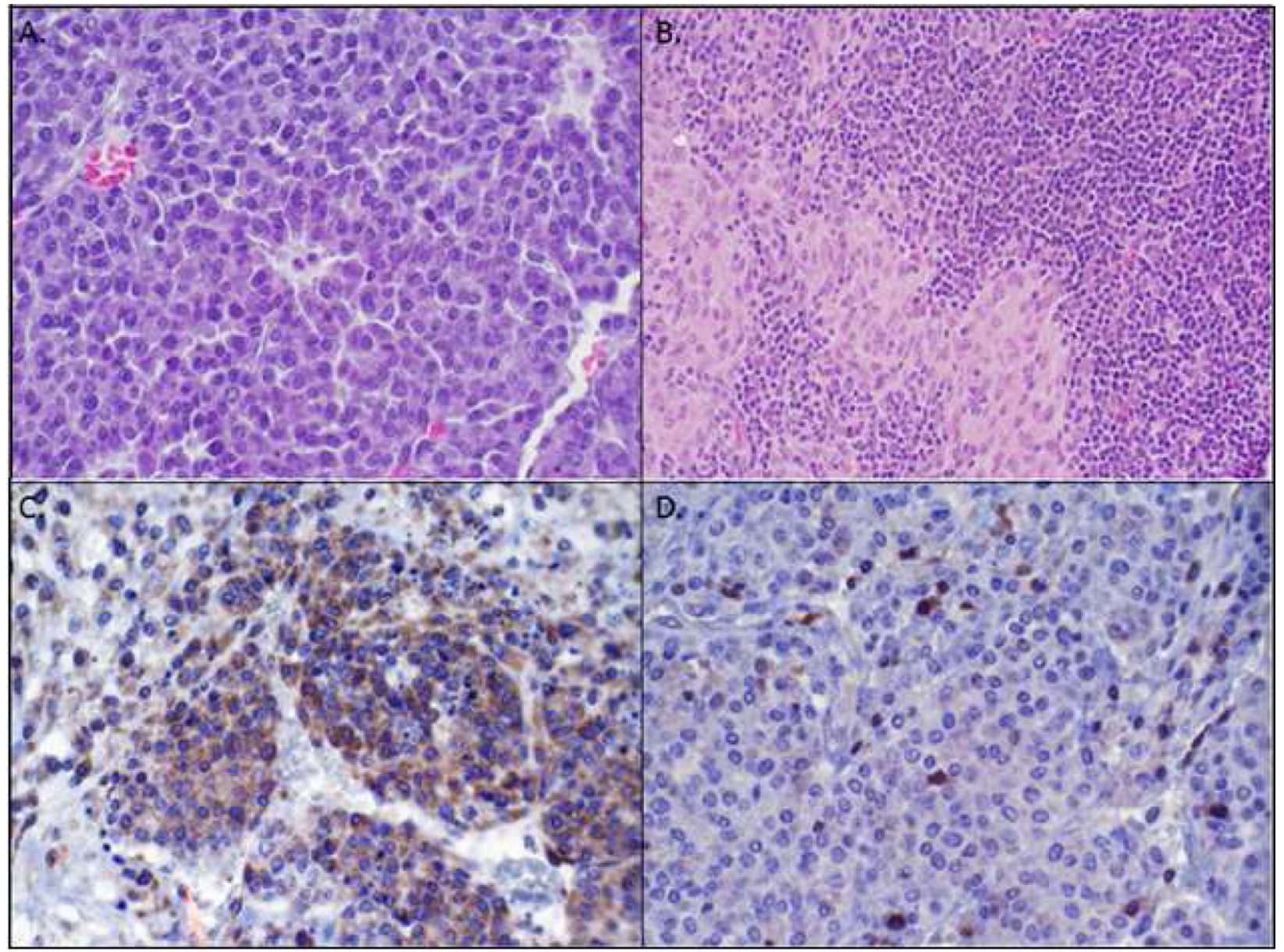

Figure 4.

A: Sheets of tumor cells forming Call-Exner bodies (40x). B: Sinus histiocytosis observed in enlarged lymph nodes both along the abdominal aorta as well as in the peripheral subcutaneous tissue (40x). C: The histologic diagnosis of granulosa cell tumor was confirmed calretinin staining $(1: 100 ; 60 x)$. D: Immunoreactivity of tumor infiltrating lymphocytes but not tumor cells for CD45 (1:20; 40x). 

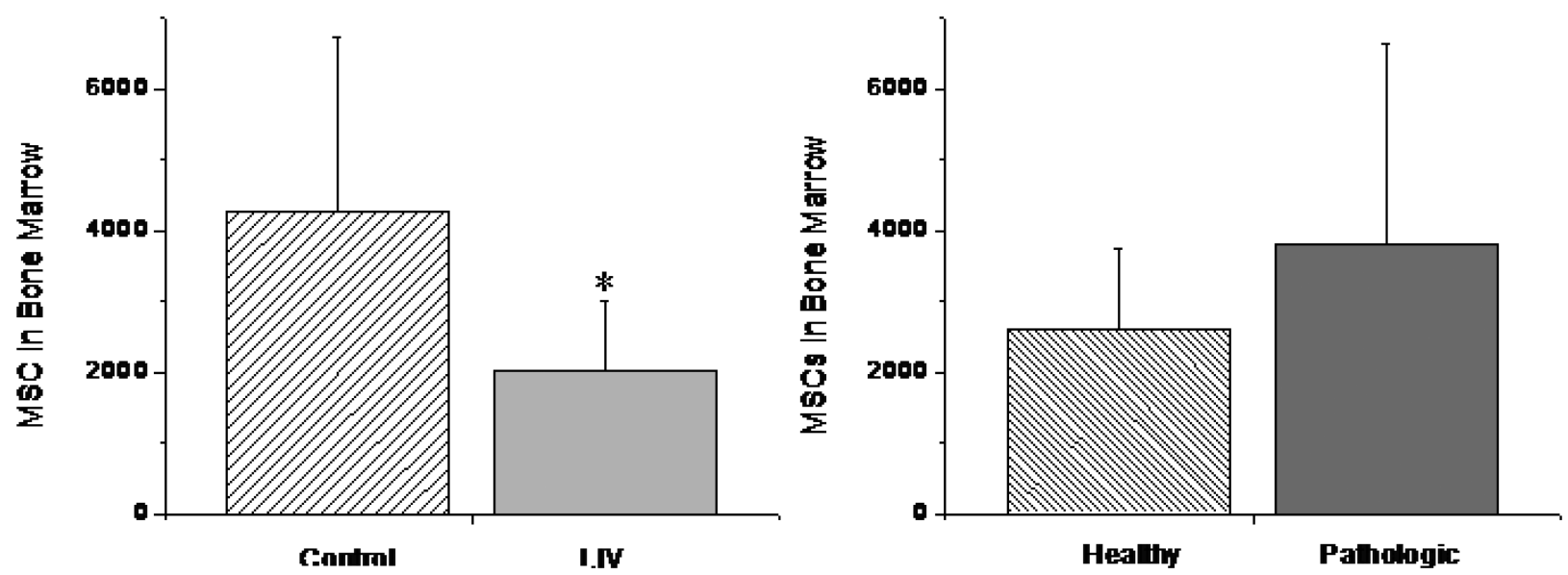

Figure 5.

MSC-enriched populations estimated from pooled hind limb bone marrow. MSC numbers were $52 \%$ lower in LIV mice as compared to age matched control (left; $p<0.01$ ), suggesting these signals either suppress MSC proliferation or promote lineage commitment towards higher-order musculoskeletal tissues. This perspective was supported when the MSC populations from diseased mice were $31 \%$ greater than those with no evidence of pathology (right; $\mathrm{p}=0.08$ ). 

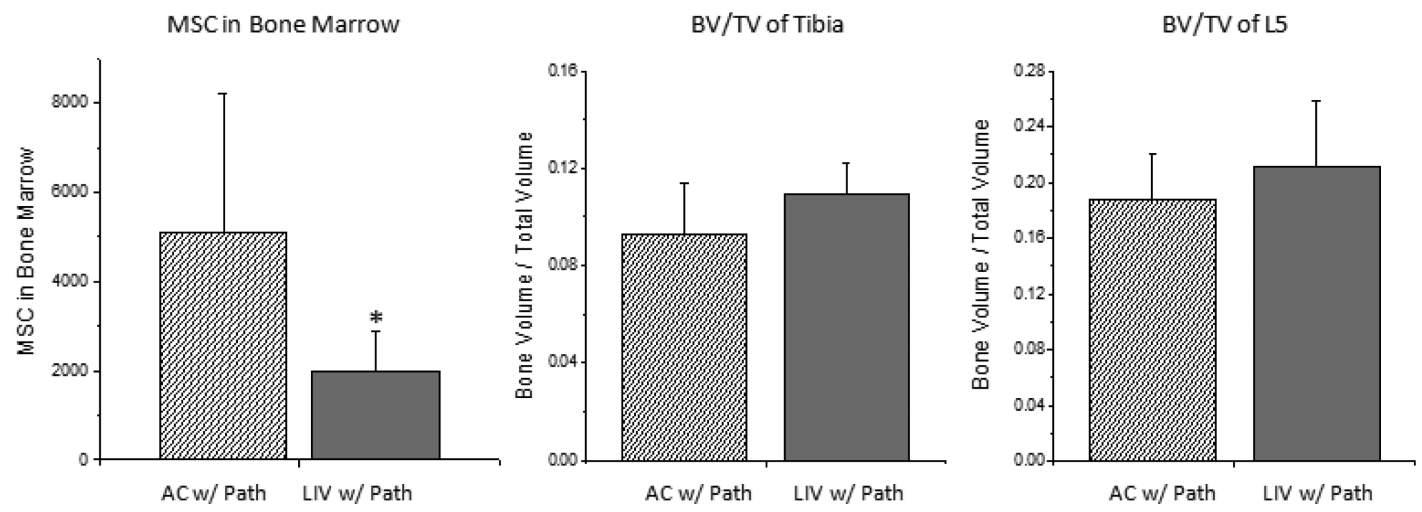

Figure 6.

When considering only those animals that had visible evidence of pathology, there were $-61 \%$ fewer MSC in the bone marrow of the LIV as compared to the AC mice (left; $\mathrm{p}<0.04)$. The BV/TV of the tibia (middle) and L5 vertebrae (right) of LIV mice with pathology showed a trend towards being higher than age-matched controls $(17 \%, \mathrm{p}=0.12$ and $13 \%$, $\mathrm{p}=0.29$, respectively). These data indicate that the mechanical signals served to suppress MSC proliferation within the bone marrow even in mice with a tumor burden, and suggest some benefit in preserving bone quality despite carrying the disease. 


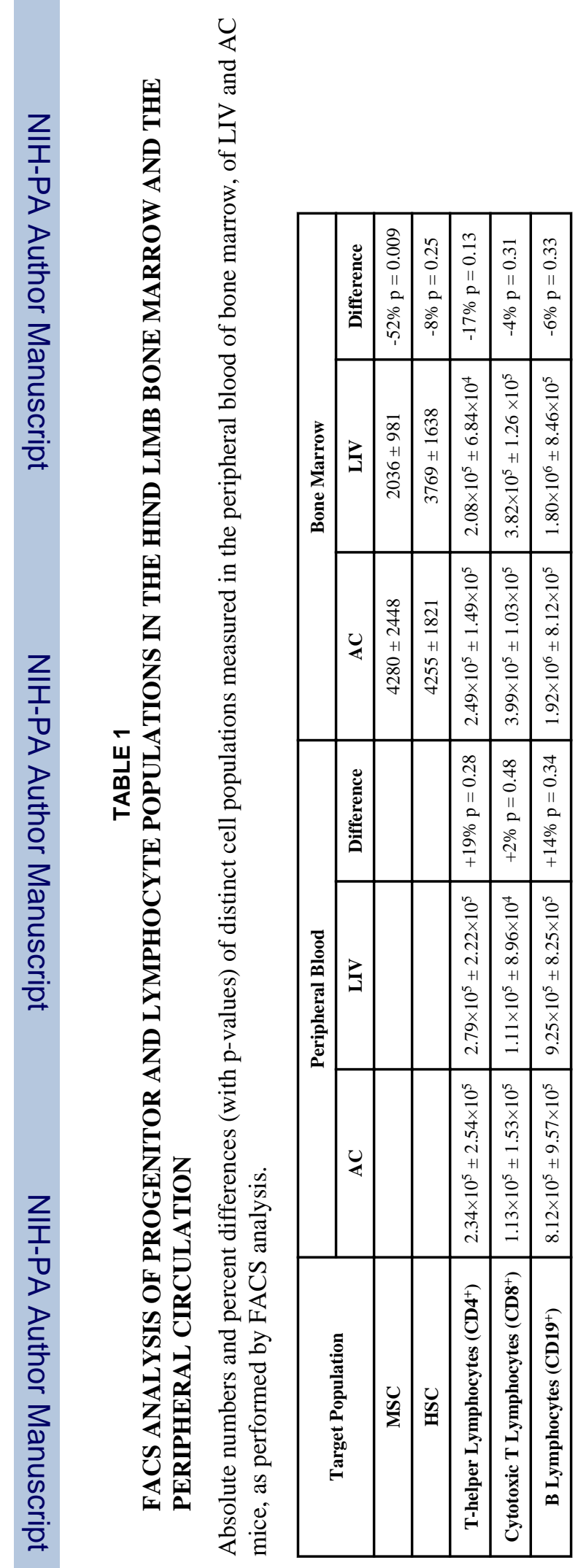

Bone. Author manuscript; available in PMC 2013 September 01. 